Preprint, the final version, of the article that has been transferred to the journal's production team.

To cite this article: Labdaoui, K., Mazouz, S., Acidi, A. E. H., Cools, M., Moeinaddini, M., \& Teller, J. (2021). Utilizing thermal comfort and walking facilities to propose a comfort walkability index (CWI) at the neighbourhood level. Building and Environment,

107627. https://doi.org/10.1016/j.buildenv.2021.107627

\title{
Utilizing thermal comfort and walking facilities to propose a Comfort Walkability index (CWI) at the neighbourhood level
}

\begin{abstract}
Many walkability indices have been developed by considering a range of specific indicators. However, comfort indicators at the neighbourhood scale and the effects of thermal comfort have generally not been accounted for in such research. To this end, we propose the comfort walkability index (CWI) at the neighbourhood micro-scale. The proposed tool is based on two questionnaires, 330 respondents answered the first questionnaire, to evaluate the relative coefficient for each indicator (Cis). The second questionnaire based on 282 respondents using a simple random sampling technique to assess the scores of the selected factors (Sis). We tested the CWI in two areas in the city centre of Annaba, Algeria, and calculated the physiological Equivalent temperature (PET) using RayMan software on two average summer days from 7 a.m. to 8 p.m. when heat and humidity peaks are observed. The results show that over $95 \%$ of the suggested indicators were estimated as being very important and necessary. The CWI scores were dependent on PET values and thermal perception. The highest scores of CWI were $40.95 \%$ and $25.23 \%$ in Colonial centre and Old town respectively, correlated with neutral thermal sensation $\left(20^{\circ} \mathrm{C}-26^{\circ} \mathrm{C}\right)$. CWI in the Colonial centre was changing from rarely acceptable comfort quality to uncomfortable level depending on PET scores; however, CWI in Old Town defined a low comfort quality despite the variability of PET scores. This paper highlights the importance of assessing pedestrian comfort facilities at the neighbourhood microscale and heeding the importance of thermal comfort in promoting a satisfying walking experience.
\end{abstract}

Keywords: Comfort Walkability Index (CWI), Hot-summer Mediterranean climate (Csa), neighbourhood scale, Physiological Equivalent Temperature (PET), thermal comfort, walkability comfort indicators. 


\section{Introduction}

Walkability refers to the suitability of an urban environment to provide pedestrian walkways [1-4]. Walkability also enhances the liveability and environmental quality of a neighbourhood [5,6], while it depends on simple infrastructure $[1,3,7,8]$. Walking is now considered a significant factor in promoting healthier, sustainable and active communities [9]. It has pertinent effects on reducing pollution in cities and ensuring inhabitants' well-being and health [10-12]. Encouraging walking environments in cities is viewed as a relevant goal in attaining sustainable mobility patterns.

A number of studies have investigated macro-level indicators at the neighbourhood scale to improve walking rates in urban areas [10-12]. Other studies have attempted to address key elements that help to create a pedestrian-friendly neighbourhood [13] by considering important factors such as safety, comfort and convenience indicators [7,14,15]. Urban furniture such as drinking fountains [16,17], slope [7,18] and benches [19,20] provide a comfortable environment for pedestrians in urban areas besides other social benefits [21-23]. Another important urban design indicator is vegetation, which has the aesthetic potential to create attractive spaces $[21,22]$. Trees that provide shade [12] encourage citizens to walk around the streets during the hot hours of the day [22]. Using the microscale approach can contribute to the provision of attractive sidewalks, pleasant and comfortable walking paths. Thus, walkability micro-scale assessment models allow us to achieve a better and more reliable perception of the walking environment [1].

From another perspective, thermal comfort can affect the use of the outdoor environment and many studies have shown the importance of climatic conditions for the wellbeing of inhabitants in outdoor environments [24,25]. People in outdoor environments are vulnerable to thermal conditions throughout the different seasons of the year, ranging from 
heat stress and cold stress to neutral and comfortable conditions. Even during a single day, people can be subject to varying levels of hot and cold thermal stress [29]. Many studies have elaborated universal indices to define thermal comfort in hot and cold conditions [26]. The two leading thermal comfort indices, the physiologically equivalent temperature (PET) and the Universal Thermal Climate Index (UTCI) have been widely used and applied to cold and hot conditions $[26,27]$. However, PET has been successfully tested in different climate zone and urban spaces such as streets, squares, parks [24,28-31]. That had been based on questionnaire confirmed by people's vote $[26,32,33]$.

Because street life and outdoor activities vary depending on the climatic conditions [34], associating thermal comfort with walkability could contribute to making streets more comfortable for pedestrians. A pedestrian-friendly environment can be developed by realizing standards and assessing walking facilities in an ongoing manner. Previous studies have linked comfort to urban design features, attractiveness and safety [7,8,35-38]. However, few studies have considered the micro-level factors at the neighbourhood scale. Moreover, walkability in urban areas has rarely been assessed using thermal comfort indices such as PET. Although there have been some developments in walkability measurement, the following practical issues related to pedestrian comfort remain unresolved: (1) the lack of methods and measurement tools that address the neighbourhood micro-scale; (2) the definitions of comfort walkability indicators; and (3) the assessment of walkability by considering thermal comfort.

Therefore, the main objective of this study is to complement the current literature by measuring walking comfort on the neighbourhood micro-level and PET values. The proposed measurement is tested in the hot-summer Mediterranean climate (Csa) of Annaba, Algeria. The novelty of this study involves the design of a new assessment tool, the Comfort Walkability Index (CWI) based on 21 pedestrian comfort indicators at the neighbourhood microscale, besides PET as a thermal comfort index. The lack of thermal comfort in 
walkability assessment tools is a challenge when the process results are to be interpreted and applied in the transport planning and urban design.

\section{Literature review}

The literature review presented in this section intended to identify the effective pedestrian- features and climatic conditions related to the comfort concept at the neighbourhood micro scale. Measurement tools and methods had been also described for a better understanding of the representative measurement of thermal comfort and walkability.

Cain et al. [39] note that there are two methods for assessing walkability at the neighbourhood scale. The first concerns macro-level characteristics, including existing structures of neighbourhoods (e.g., street connectivity, land-use mix, residential density) that are not exposed to frequent changes in the urban environment [40]. The second approach is related to the micro-level at the neighbourhood scale, consisting of the quality and attractiveness of sidewalks, which can affect the comfort and safety of walkability in urban spaces $[7,35,41]$. However, the micro-level approach at the neighbourhood scale, which can more easily account for frequent changes than at the macro level, has rarely been explored [39]. Moreover, it is essential to identify pedestrian amenities in relation to the quality of the walking environment [7]. Thermal comfort assessment at the neighbourhood micro-level is thus a promising quantitative approach to estimate pedestrian comfort because of its straightforward measurement.

Streets, sidewalks, parks, squares and other urban design elements can play a crucial role in promoting walkability, as they can affect pedestrian walking behaviour $[9,40,42]$. Furthermore, sidewalk amenities conducive to comfortable walking involve main facilities (e.g., kerbs, ramps, sidewalk width), encouragement facilities (e.g., lighting, sitting areas, landscaping and trees) and convenience facilities (e.g., toilets, drinking fountains) [1]. Such indicators can transform spaces into accessible, walkable and comfortable areas $[1,4,45,46]$. 
Aghaabbasi et al. [8] divided walkability indicators into different components, such as accessible design factors (e.g., accessible drinking fountains, accessible toilets, tactile pavements, kerb ramps, accessible signage and signals, skybridge lifts); safety design factors (e.g., landscaping and trees, signage, bollards, surfaces and materials, lighting, signals); attractiveness design factors (e.g., landscaping and trees, benches and sitting areas, rubbish bins, effective sidewalk width, lighting, cleanliness); and sidewalk path conditions (e.g., maintenance, slope, natural barriers). Other studies have used similar walkability indicators, such as seating areas, bollards, landscaping and trees, toilets, rubbish bins, skybridge lifts, driveways, slope, materials/surfaces, effective sidewalk width, signals, signage, tactile pavements, ramps, kerb ramps, cleanliness, lighting [7], drinking fountains [1], shady trees, accessibility to green spaces, benches and pedestrian-scale lighting [43-47].

According to Asadi-Shekari et al. [43], improvement in sidewalk conditions can be achieved by integrating certain walkability factors such as the following: slower traffic, midblock crossings, landscaping and trees, facilities (e.g., fire hydrants), lighting, signals, bollards, slope, kerb ramps, wheelchair-accessible drinking fountains, tactile pavements (warning and guiding), signals, benches and seating areas. These walkability indicators are suitable for all users, including people with disabilities.

It can be concluded that most existing studies have focused on attractive design features, safety, usability and convenience design factors at the street level. Few studies have explored comfort at the neighbourhood scale. We, therefore, propose a wide range of comfort indicators for the neighbourhood micro-scale level.

\subsection{Assessment of walkability tools}

In recent years, numerous studies have adopted an objective approach to the evaluation of walkability. The complexity of the relationship between neighbourhood micro- 
scale indicators and walking behaviour, and in addition the role of individual perception, form an elaborate framework that researchers have tried to resolve.

The Path Environment Audit Tool (PEAT) [48] uses a variety of walkability indicators at the micro-scale level; however, many comfort indicators such as sidewalk material and width, as well as trees and shade, are not considered. The Walking Suitability Assessment Form (WSAF) [49] and the PIN3 Neighbourhood Audit Instrument [50] examine a restricted number of walkability indicators and focus on the presence of trees and shading effects on the walking area and street lighting; however, many comfort factors are not included (e.g., toilets, slope, fountains, benches, seated drinking fountains, toilets, slope benches, seats). The Neighbourhood Environment Walkability Survey (NEWS) [51] is the most commonly used tool in survey question formats, and includes a number of walkability indicators such as lighting, cleanliness and separation of pedestrians and vehicles (buffering). However, NEWS also lacks certain comfort indicators (e.g., drinking fountains, tactile pavements, toilets).

Clifton et al. [20] proposed the Pedestrian Environment Data Scan (PEDS) tool, which includes abroad range of indicators (e.g., path material, path condition, slope and path obstructions), although, again, many comfort indicators are missing (e.g., drinking fountains, slope and kerbs). Aghaabbasi et al. [7] focused on the Neighbourhood Sidewalk Assessment Tool (NSAT), which considers a wide variety of comfort indicators besides extended pedestrian categories, leading to increased satisfaction among people with different physical abilities. Overall, there is a generalised lack of use of comfort indicators in the assessment of walkability in measures such as PIN3, PEAT, NEWS and PEDS, besides the exclusion of consideration of people with disabilities.

Asadi-Shekari et al. [35] reported that the pedestrian level of service (PLOS) was found to be a useful measurement tool. This measure helps designers and planners to evaluate the quality of the street environment for pedestrians and can provide guidance regarding 
enhancements to solve existing problems. Although some studies have used PLOS to assess sidewalk capacity [35], PLOS models have generally focused on the street characteristics involving micro-design factors and pedestrian amenities [14,35,41,43].

The different methods described above have been used according to the respective research objectives. Because most of these objectives focused on the street level, few methods are available for the neighbourhood micro-scale level.

\subsection{Thermal comfort}

In recent years, researchers have paid particular attention to thermal comfort in urban environments and its effect on inhabitants [25,26,33,52-54]. Numerous studies have attempted to define thermal comfort conditions to determine the concept of thermal sensation in outdoor urban spaces $[24,53,55-59]$. Thermal comfort is referred to as user satisfaction regarding the thermal environment $[26,60]$.

Understanding microclimate environment characteristics is important because they influence people's comfort and outdoor activities [24]. Some studies have focused on the development of universal indices that can measure thermal comfort in hot and cold climates [24,26]. Indices such as Perceived temperature (Pt) [26,61], Standard Effective Temperature (SET*) [26,62] and its outdoor variant OUT-SET* [63], UTCI [64], PET [68,69] and predicted mean vote (PMV) [26,67-69] have been effectively applied to urban areas for thermal comfort assessment.

Most current indices for outdoor thermal perception include PET, PMV, UTCI and SET* [26], and these are suitable for calculating heat and cold stress. PMV allows the classification of thermal sensation; PET, UTCI and SET* provide an evaluation in ${ }^{\circ} \mathrm{C}$ of thermal sensation. SET* is a more suitable index for hot climates, whereas PET and UTCI are typically employed in both hot and cold climates [27]. 
According to Chen and Matzarakis. [70], UTCI used $135 \mathrm{~W} / \mathrm{m}^{2}$ as reference activity. It highlights the relevance of the effect of air humidity and wind speed concern. The initial scaling for UTCI was based on the multi-node dynamic-thermo physiological UTCI - Fiala model [71]. While PET used $80 \mathrm{~W} / \mathrm{m}^{2}$ as a standard stimulating activity, experimental studies showed that people feel usually much heated under brutal metabolism than slight metabolism [70]. The original scaling for PET was based on human energy balance [72], besides PET focuses on radiant and sensible heat loss [70].

PET had been less criticized in comparison with UTCI, according to Potchter et al. [26], the examination of the relation between PET and full scale and outdoor thermal conditions showed a positive relationship and demonstrated a strong correlation. Many field surveys based on questionnaires have been undertaken in different climatic zones, searching to validate those indices against actual people's votes [24,32,33], while the exploration of the relation between UTCI full scale and outdoor thermal conditions highlighted a positive and weak relation, identified as not correlative and significant due to the limited sample size [26]. Besides a few studies tested the subjective method, which the results showed a different scale of no stress category (comfort range) for the different climatic condition, that should be examined according to Potchter et al.[26]. In comparison PET had been validated in several climatic zones [27,28,31,65] and investigated in a wild range of outdoor environments $[30,31,53,75]$.However, the verification of the PET and UTCI indices shows that the perceived comfort zone values are very similar to each other [26].

PET was introduced in Western and Central Europe [24,55,78]; The "neutral" scale for the PET index in hot climates of $24-26^{\circ} \mathrm{C}$ was confirmed in $95 \%$ of studies. In a cold climate, $89 \%$ of studies showed a "neutral" range of $15-20^{\circ} \mathrm{C}$. Lin [79] examined thermal sensation and its adaptation to the tropical climate in Taiwan and reported PET values of $21.3-28.5^{\circ} \mathrm{C}$ all year round, which were higher than the European scale PET values of $18-23^{\circ} \mathrm{C}$. Another 
study in the Csa of Tel Aviv, Israel, demonstrated that the PET values were higher than the European PET scale by $3^{\circ} \mathrm{C}$ and lower by $5^{\circ} \mathrm{C}$ than the lower boundary of the PET values recorded in Taiwan [24]. Mahmoud [29] studied thermal comfort in an urban park in Cairo, Egypt, where the PET values were $22-30^{\circ} \mathrm{C}$ in summer and $21-29^{\circ} \mathrm{C}$ in winter, which were also higher than the European scale [26]. These results demonstrated the influence of urban climatic characteristics on human balance, energy and people's thermal perception, all of which affect the use of outdoor environments [55]. These studies thus highlight the impact of the duality of microclimatic measurement and thermal perception in cities and the use of the outdoor environment in different climates.

Based on this literature review, we strongly support the feasibility of including thermal comfort in the assessment of walkability. This study seeks to develop an innovative approach towards inclusive design features and thermal comfort for a pleasant walking experience. We focus on universal comfort factors at the neighbourhood micro-scale level, in addition to a broad range of user categories, and consider PET as a thermal comfort index, that had been calculated based on climatic data such as air temperature, relative humidity and wind velocity on two representative summer days. Our method had been tested in the city of Annaba, Algeria, which is characterised by a Csa climate. Moreover, relating walkability scores to people's perception of the pedestrian environment and thermal sensation in a Csa climate provides a better understanding of the pedestrian comfort rating.

\section{Method}

Several methodologies have been developed and applied in urban planning to integrate pedestrian audits in transportation system plans and pedestrian planning. To date, however, there are few data gathered using walkability measurement methods that involve the neighbourhood micro scale. We now briefly present each of the main steps of the CWI procedure. Figure 1 provides a comprehensive description. 


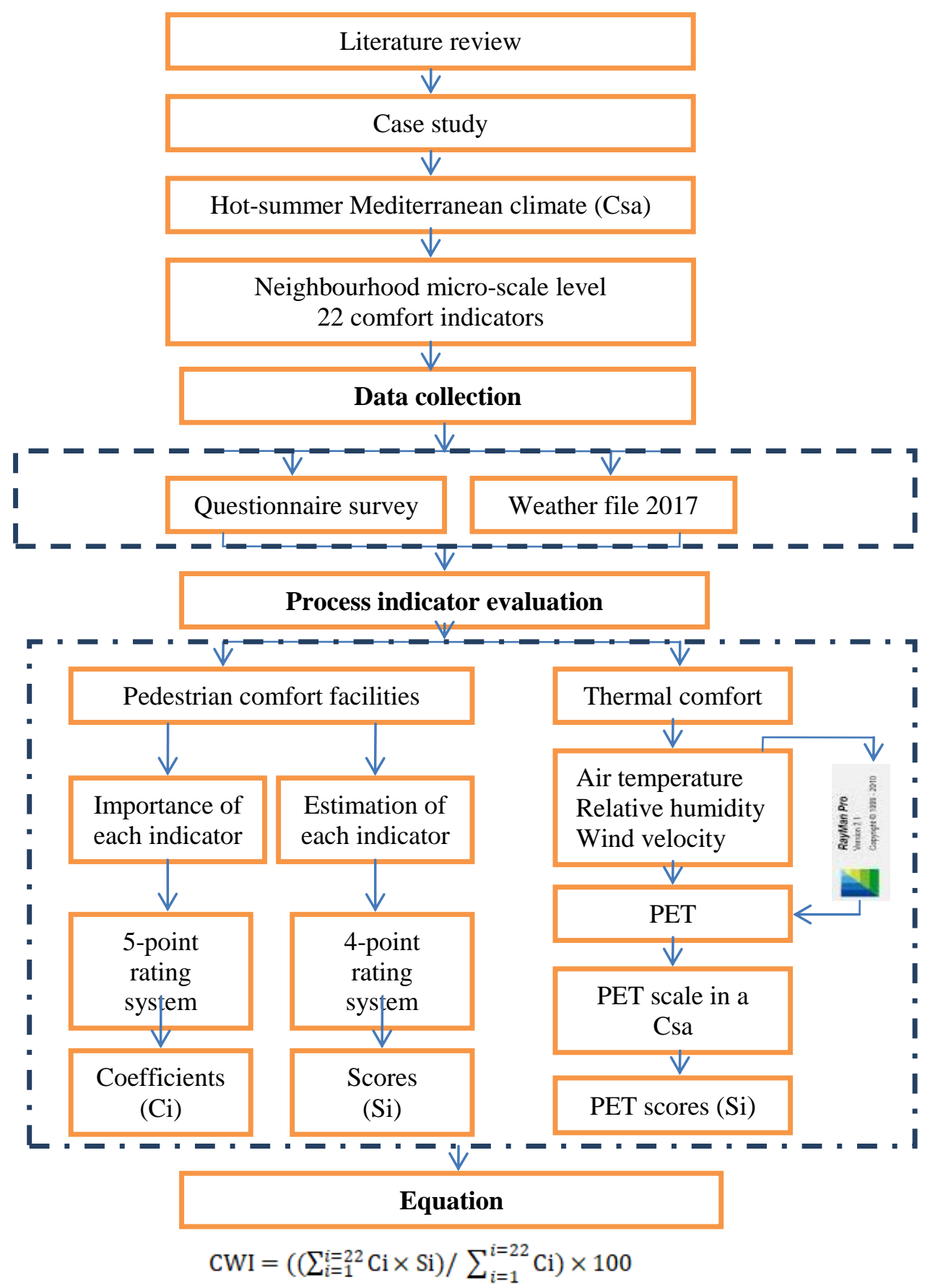

Fig. 1.Conceptual framework of the comfort walkability index (CWI).

\subsection{Review of effective indicators}

This research paper involved the identification of indicators in full research papers, review articles and standard guidelines, using Google Scholar, the Web of Science and weather records. Keywords included walkability, thermal comfort, assessment tools, streets, 
neighbourhood and Csa. Some papers were omitted because they focused on collecting data related to the trip level, and as a result, there was a lack of information regarding tool assessment and application. According to our criteria, the selected indicators concerned research conducted between 2002 and 2019, with the aim of defining the comfort indicators that promoted enjoyment of a pleasant walking experience. This concept was analysed on neighbourhood and street scales, as well as the widely used index of thermal comfort in outdoor environments. The findings highlighted the gap in research on the neighbourhood micro-scale regarding the evaluation of thermal comfort in walkability. The relevant comfort indicators are presented in Table 1.

Table 1. List of pedestrian comfort indicators appropriate for the neighbourhood micro scale.

\begin{tabular}{cc}
\hline Pedestrian comfort indicators & References \\
Slower traffic speed & {$[43,36]$} \\
Buffer and barriers (kerb and furnishing zone) & {$[43,36]$} \\
Fewer traffic lanes & {$[43,36]$} \\
Mid-block crossings & {$[36]$} \\
Landscaping and trees & {$[1,35,43,36,8,7]$} \\
Furniture (rubbish bins) & {$[1,35,43,7]$} \\
Footpath pavement & {$[36,9,38]$} \\
Marking (crosswalk) & {$[36]$} \\
Sidewalks on both sides & {$[36]$} \\
Footpath width & {$[1,35,43,7]$} \\
Slope & {$[43,8,7]$} \\
Lighting & {$[1,35,43,36,8,7]$} \\
Ramp & {$[1,35,43,36,7]$} \\
Parks and spaces for playing & {$[80,81]$} \\
Social spaces (cafés) & {$[9,82]$} \\
Shade & {$[12,20]$} \\
Benches and seating areas & {$[1,35,43,7]$} \\
Toilets & {$[1,8,7]$} \\
Pedestrian signals & {$[35,43,36,8,7]$} \\
Shorter crossing distance (kerb extension) & {$[36]$} \\
\hline
\end{tabular}

\subsection{Data collection}

For data collection, we conducted two surveys, one with pedestrians and the other via an online platform (Monkey, Google Forms). It is worth noting that the participants who answered on online platforms were very familiar with the selected neighbourhood as they are 
residents. Besides general information (age, sex, education), the questionnaire focused on the importance of pedestrian comfort facilities and the status of each indicator in the selected neighbourhoods. The respondents were asked to classify the importance of the chosen factors and estimate their actual condition.

\subsection{Assessing indicators}

To evaluate the indicators, we calculated coefficients and scores from the survey results, as well as a suitable model for designing walkable neighbourhoods. Climate data such as air temperature, wind velocity and relative humidity were used to calculate PET values using RayMan software. We chose two representative summer days to explore the micro differences in the same season characterised by a Csa. Finally, we calculated the CWI using a point system; the related scoring method for PLOS followed Asadi-Shekari et al. [36,41,43]. The CWI score can be calculated from Eq. (1):

$$
\mathbf{C W I}=\left(\left(\sum_{i=1}^{i=22} \mathrm{Ci} \times \mathrm{Si}\right) / \sum_{i=1}^{i=22} \mathrm{Ci}\right) \times 100,
$$

Where $\boldsymbol{C} \boldsymbol{i}$ is the coefficient of each indicator and $\boldsymbol{S i}$ is the score of each indicator.

Table 2 shows the different classifications of the CWI percentage rating and their interpretations. CWI A shows the highest comfort quality conditions. CWI B may be acceptable considering the availability of some comfort indicators besides the feasibility of some operational improvements. CWI C requires more attention and improvement. CWI D indicates inferior quality and uncomfortable conditions, requiring considerable improvement. CWI E and F are the worst comfort quality and lack of standard pedestrian facilities; therefore, they require significant improvement. 
Table 2. Interpretation of CWI rating.

\begin{tabular}{|c|c|c|}
\hline $\begin{array}{l}\text { CWI \% } \\
\text { rating }\end{array}$ & $\begin{array}{l}\text { Model } \\
\text { score }\end{array}$ & Interpretation \\
\hline A & $80-100$ & $\begin{array}{c}\text { Highest comfort quality (very pleasant), many pedestrian comfort facilities } \\
\text { present. }\end{array}$ \\
\hline B & $60-79$ & High comfort quality (acceptable), some pedestrian comfort facilities present. \\
\hline $\mathrm{C}$ & $40-59$ & $\begin{array}{l}\text { Average comfort quality (rarely acceptable), pedestrian comfort facilities } \\
\text { present; however, there is potential to improve pedestrian comfort conditions. }\end{array}$ \\
\hline $\mathrm{D}$ & $20-39$ & Low quality (uncomfortable), minimal pedestrian comfort facilities. \\
\hline $\mathrm{E}$ & $1-19$ & Lowest comfort quality (unpleasant). \\
\hline $\mathrm{F}$ & 0 & No standard pedestrian amenities (very uncomfortable). \\
\hline
\end{tabular}

For thermal comfort, we selected PET for its various benefits in outdoor urban spaces

- PET was applied and approved in multiple urban areas with detailed shading design; precise averages for thermal environments were thus obtained [27,28, $30,31]$.

- PET was compared and related to the mean thermal sensation vote (MTSV) scale across multiple climatic zone classifications [24,55,69,83-85] and used for improving outdoor thermal comfort ratings in hot and cold climates.

- PET was validated in different climatic zones using multiple field surveys based on population responses $[25,33,55,76]$, which makes it reliable.PET was legally approved as a human biometeorological climate assessment tool for urban and regional planning, according to the German standard VDI 3787 (VDI,1998) [55].

- PET was calculated using software packages (e.g., RayMan, ENVI-met) and considering climatic/microclimatic data (air temperature, relative humidity, wind speed, average radiant temperature).

- PET had been explored and proved at the street level $[55,24,86,58,71]$, and correlated to the pedestrian thermal comfort term.

We validated the relevance of the listed indicators and thermal comfort within the Csa using the method described below. 


\subsection{Data collection}

The selected indicators were the subject of two specific questionnaires for data collection: the first focused on the importance of comfort design features at the neighbourhood micro scale, and the second included the participants' evaluation of each indicator.

The climate data (air temperature, relative humidity and wind velocity) were acquired from the Annaba weather records 2017 on two representative summer days (18 July and 8 August 2017) when air temperatures and the relative humidity reach their peak.

\subsection{Process indicator evaluation}

\subsubsection{Pedestrian comfort facility coefficients and scores}

The first questionnaire evaluates the importance of 21 indicators at the neighbourhood micro-scale level using a five-point Likert scale ranging from 1 (least important) to 5 (very important). In total, 330 respondents from different cities in Algeria including Annaba answered the first questionnaire using an online platform. The outputs of this questionnaire are used to generate the relative coefficient for each comfort indicator (Cis). The second questionnaire (282 respondents) assesses the scores of the selected factors (Sis), using a simple random sampling technique. The randomised information allowed us to define the respondents' characteristics (e.g., sex, age, residential origin), while participants evaluated each indicator using a scale ranging from 0 (awful) to 4 (very good).

\subsubsection{Calculating and scoring PET}

\subsubsection{Calculating PET}

This study used RayMan software to calculate PET values from 7 a.m. to 8 p.m. (every hour) on two representative summer days. This software, which was developed in accordance with guidelines of the German Engineering Society [87] at the University of 
Freiburg, Germany, is regarded as one of the most reliable radiation and bioclimate models $[24,55]$ to predict thermal comfort and has been approved for use in urban spaces and several climatic zones [29,34,36,59,84].

RayMan measures PET based on air temperature, air humidity, wind speed, mean radiant temperature, clothing and human activity. The period of the year, time of day and environmental obstacles allow the sky view factor (SVF) to be calculated. It can also be adjusted to account for other variables, such as the albedo of the surrounding surfaces, altitude and location, the Bowen ratio of the ground surface and the related air turbidity $[30,55,56]$. The software manufacturer recommends that for the assessment of thermal sensation, constants should be adjusted based on a man with a height of $1.75 \mathrm{~m}$ and a weight of $75 \mathrm{~kg}$ $[24,66]$. PET calculation is based on representative segments of each neighbourhood, with every street having a PET calculating point. The PET value in each neighbourhood is the average of the calculated points (Fig. 2).

\subsubsection{Scoring PET}

To score PET in a Csa, a scale from 0 to 1 was adopted according to the TSV defined in Tel Aviv, which is characterised by a Csa. The thermal comfort range that reflects a neutral sensation of the TSV classification is estimated at between $19^{\circ} \mathrm{C}$ and $25^{\circ} \mathrm{C}$ for winter, and between $20^{\circ} \mathrm{C}$ and $26^{\circ} \mathrm{C}$ in the summer [24]. For cold and hot and very hot the score of PET is 0; for cool and warm, 0.25; for slightly cool and slightly warm, 0.5; and for the neutral thermal sensation, 1 (see Tables 3 and 4). 
Table 3. Thermal sensation and PET range for Tel Aviv (Csa) $[77,89,90]$.

\begin{tabular}{cccc}
\hline TSV & Thermal sensation & $\begin{array}{c}\text { PET range for Tel Aviv } \\
\left({ }^{\circ} \mathbf{C}\right)\end{array}$ & $\begin{array}{c}\text { Tel Aviv climatic zone } \\
\text { (Köppen classification) }\end{array}$ \\
\hline-4 & Very cold & - & \\
-3 & Cold & 8 & \\
-2 & Cool & 12 & \\
-1 & Slightly cool & 15 & Csa \\
0 & Neutral & 19 & \\
1 & Slightly warm & 26 & \\
2 & Warm & 28 & \\
3 & Hot & 34 & \\
4 & Very hot & 40 & \\
\hline
\end{tabular}

${ }^{a}$ Subtropical (Csa) ; TSV, thermal sensation vote scale.

Table 4. PET scores according to thermal sensation and PET range in a Csa.

\begin{tabular}{cc}
\hline PET range & PET scores \\
\hline $8-12^{\circ} \mathrm{C}$ & 0 \\
$12.1-15^{\circ} \mathrm{C}$ & 0.25 \\
$15.1-19^{\circ} \mathrm{C}$ & 0.5 \\
$19.1-26^{\circ} \mathrm{C}$ & 1 \\
$26.1-28^{\circ} \mathrm{C}$ & 0.5 \\
$28.1-34^{\circ} \mathrm{C}$ & 0.25 \\
$34.1-40^{\circ} \mathrm{C}$ & 0 \\
\hline
\end{tabular}

\subsection{Case study}

The field study was conducted in the city of Annaba, Algeria $\left(36^{\circ} 54^{\prime} \mathrm{N}, 7^{\circ} 46^{\prime} \mathrm{E} ;+5 \mathrm{~m}\right.$ above sea level) with a population of 640,050 (National Office of Statistics, 2008). Annaba is characterised by a hot-summer Mediterranean climate (Csa) according to the Köppen [91] classification. In the 2015-2019 period, the air temperature varied from $12^{\circ} \mathrm{C}$ to $22^{\circ} \mathrm{C}$ (maximum) and $4^{\circ} \mathrm{C}$ to $11^{\circ} \mathrm{C}$ (minimum) in winter, and the maximum summer air temperature varied from $26^{\circ} \mathrm{C}$ to $36.5^{\circ} \mathrm{C}$. The minimum summer temperature varied from $15^{\circ} \mathrm{C}$ to $24^{\circ} \mathrm{C}$. The Colonial Centre and the Old Town (Medina) are located in Annaba city centre, and they are rated as the most walkable neighbourhoods (66\% and $64 \%$ walking scores, respectively, based on [92]). In addition, a dense commercial area means that the city centre plays a significant role. 
PET calculation is based on representative segments of each neighbourhood according to the following criteria: street hierarchy, street width, standard sidewalks, slight slope, the height of buildings, street orientation, street length, and vegetative species and their distribution.

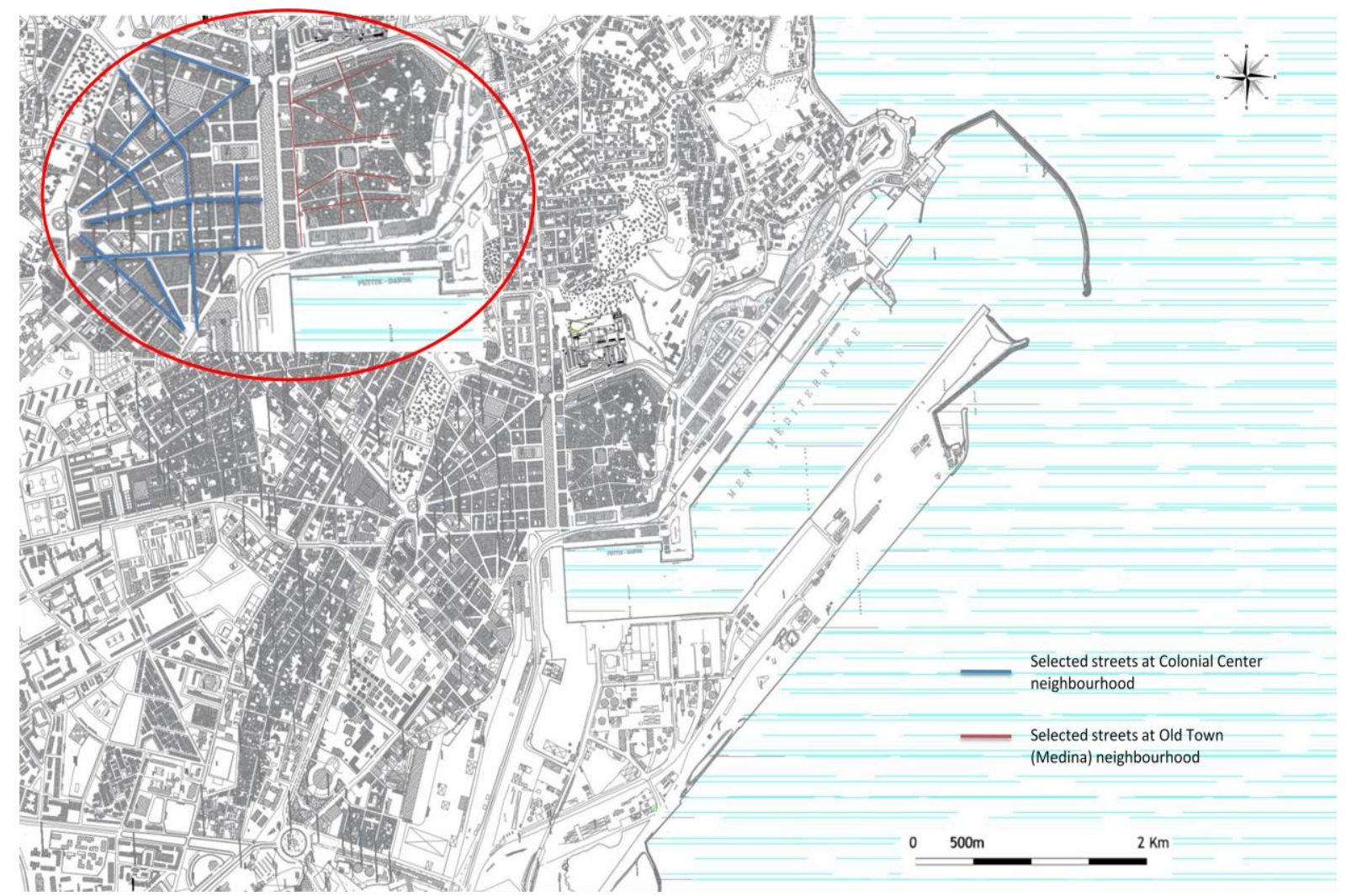

Source: PDAU Annaba, 2004

Fig 2 Selected streets at Colonial Center and Old Town in Annaba city centre.

\section{Results}

Distinct neighbourhoods regardless of their characteristics can be evaluated using the CWI model, as the indicators and standards are from leading models and current research. We studied two areas to test the CWI model; the PET values of each neighbourhood are taken from average PET values of selected streets. 


\subsection{Pedestrian comfort facility coefficients and scores}

Table 5 shows the results of coefficients and scores at the neighbourhood micro scale. Each neighbourhood had four representative streets characterised by their length varying between $230 \mathrm{~m}$ and $510 \mathrm{~m}$ in the Colonial Centre, and between $116 \mathrm{~m}$ and $428 \mathrm{~m}$ in the Old Town along different orientations: North, South, East, West, North-west-South-east and North-east-South-west. The selected streets in each neighbourhood were used to get the neighbourhood representative PET based on street computing point. In total, 21 pedestrian facilities in addition to thermal comfort were tested at the neighbourhood micro scale.

According to the survey results, $95 \%$ of the indicators were considered very important and necessary, with coefficients of $0.80-0.93$ and $0.67-0.77$, respectively (e.g., landscaping and trees, footpath pavement ramps, pedestrian signals, footpath width, slope); the exception was one indicator (rubbish bins) that was viewed as less critical (coefficient of 0.32). The perception of participants varied from very good, good, some problems, many problems to awful, with respective scores of $0.79,0.52-0.65,0.4-0.47,0.2-0.39$ and $0.14-0.18$. The scores for the Colonial Centre were higher than those for the Old Town (Fig. 3).

Most of the pedestrian facilities in the Colonial Centre scored highly, indicating their pleasant condition (0.60-0.79) (e.g., benches and seating areas, slope, social spaces, landscaping and trees, footpath pavements), although there were some exceptions (facilities such as lighting, ramps). In contrast, few indicators were estimated as good in the Old Town, with the highest score assigned to shade. Most pedestrian facilities received low scores of 0.18-0.23 (e.g., benches and seating areas, footpath width, landscaping and trees, ramps, parks, spaces for playing) reflecting their awful condition (Table 5).

Analysis of the comfort indicator scores in the Colonial Centre shows that PET values achieved both the maximum score of 1 and the lowest score of 0 , compared with pedestrian comfort facilities where benches and seating areas earned the highest score of 0.79 versus 
ramps, which were evaluated with the lowest score of 0.2 (Fig. 4). In the Old Town, PET values also achieved both the maximum score of 1 and the lowest score of 0 , compared with shade, with a score of 0.54 , and toilets, with a score of 0.14 (Fig. 5). 
Table 5. Scores and coefficients of walkability comfort indicators in two selected areas.

\begin{tabular}{|c|c|c|c|c|c|c|c|c|}
\hline & \multicolumn{4}{|c|}{ Colonial Centre neighbourhood } & \multicolumn{4}{|c|}{ Old Town neighbourhood } \\
\hline \multirow{3}{*}{$\begin{array}{c}\text { Orientation } \\
\text { Street length } \\
\end{array}$} & Street 1 & Street 2 & Street 3 & Street 4 & Street 5 & Street 6 & Street 7 & Street 8 \\
\hline & $\mathrm{NE} / \mathrm{SW}$ & E/W & $\mathrm{N} / \mathrm{S}$ & NW/SE & $\mathrm{N} / \mathrm{S}$ & $\mathrm{E} / \mathrm{W}$ & NE/SW & NW/SE \\
\hline & $510 \mathrm{~m}$ & $435.43 \mathrm{~m}$ & $410.26 \mathrm{~m}$ & $230.46 \mathrm{~m}$ & $427.66 \mathrm{~m}$ & $239.21 \mathrm{~m}$ & $115.84 \mathrm{~m}$ & $163.96 \mathrm{~m}$ \\
\hline Indicators & \multicolumn{2}{|c|}{ Coefficient } & \multicolumn{3}{|c|}{ Average scores at Colonial Centr } & \multicolumn{3}{|c|}{ Average scores at Old Town } \\
\hline Landscaping and trees & \multicolumn{2}{|c|}{0.93} & \multicolumn{3}{|c|}{0.62} & \multicolumn{3}{|c|}{0.23} \\
\hline Footpath pavement & \multicolumn{2}{|r|}{0.92} & \multicolumn{3}{|c|}{0.6} & \multicolumn{3}{|c|}{0.25} \\
\hline Parks and spaces for playing & \multirow{2}{*}{\multicolumn{2}{|c|}{0.85}} & \multirow{2}{*}{\multicolumn{3}{|c|}{0.52}} & \multirow{2}{*}{\multicolumn{3}{|c|}{0.18}} \\
\hline Shade/thermal comfort & & & \multirow{2}{*}{\multicolumn{3}{|c|}{$\begin{array}{l}0.59 \\
0.55\end{array}$}} & \multirow{2}{*}{\multicolumn{3}{|c|}{0.54}} \\
\hline Markings (crosswalk) & \multicolumn{2}{|r|}{$\begin{array}{l}0.85 \\
0.84\end{array}$} & \multirow{2}{*}{\multicolumn{3}{|c|}{$\begin{array}{l}0.55 \\
0.79\end{array}$}} & \multirow{2}{*}{\multicolumn{3}{|c|}{$\begin{array}{l}0.26 \\
0.39\end{array}$}} \\
\hline Benches and seating areas & \multicolumn{2}{|r|}{0.84} & & & & & & \\
\hline Toilets & \multicolumn{2}{|r|}{0.82} & \multicolumn{3}{|c|}{0.54} & \multicolumn{3}{|c|}{0.14} \\
\hline Buffer and barriers (kerbs and furnishing zone) & \multicolumn{2}{|r|}{0.80} & \multicolumn{3}{|c|}{0.52} & \multicolumn{3}{|c|}{0.25} \\
\hline Social spaces (cafés) & \multicolumn{2}{|r|}{0.80} & \multicolumn{3}{|c|}{0.62} & \multicolumn{3}{|c|}{0.47} \\
\hline Sidewalk on both sides & \multicolumn{2}{|r|}{$\begin{array}{l}0.80 \\
0.77\end{array}$} & \multirow{2}{*}{\multicolumn{3}{|c|}{$\begin{array}{c}0.59 \\
0.2\end{array}$}} & & 0.33 & \\
\hline Ramps & & 0.77 & & & & & 0.18 & \\
\hline Mid-block crossings & & 0.76 & & 0.38 & & & 0.21 & \\
\hline Pedestrian signals & & 0.76 & & 0.59 & & & 0.43 & \\
\hline Width of footpaths & & 0.75 & & 0.47 & & & 0.25 & \\
\hline Shorter crossing distances (kerb extension) & & 0.73 & & 0.4 & & & 0.34 & \\
\hline Slower traffic speed & & 0.72 & & 0.23 & & & 0.24 & \\
\hline Slope & & 0.71 & & 0.65 & & & 0.41 & \\
\hline Lighting & & 0.69 & & 0.34 & & & 0.2 & \\
\hline Fewer traffic lanes & & 0.68 & & 0.46 & & & 0.28 & \\
\hline Standard driveways & & 0.67 & & 0.37 & & & 0.22 & \\
\hline Furniture and facilities (rubbish bins) & & 0.32 & & 0.61 & & & 0.51 & \\
\hline
\end{tabular}




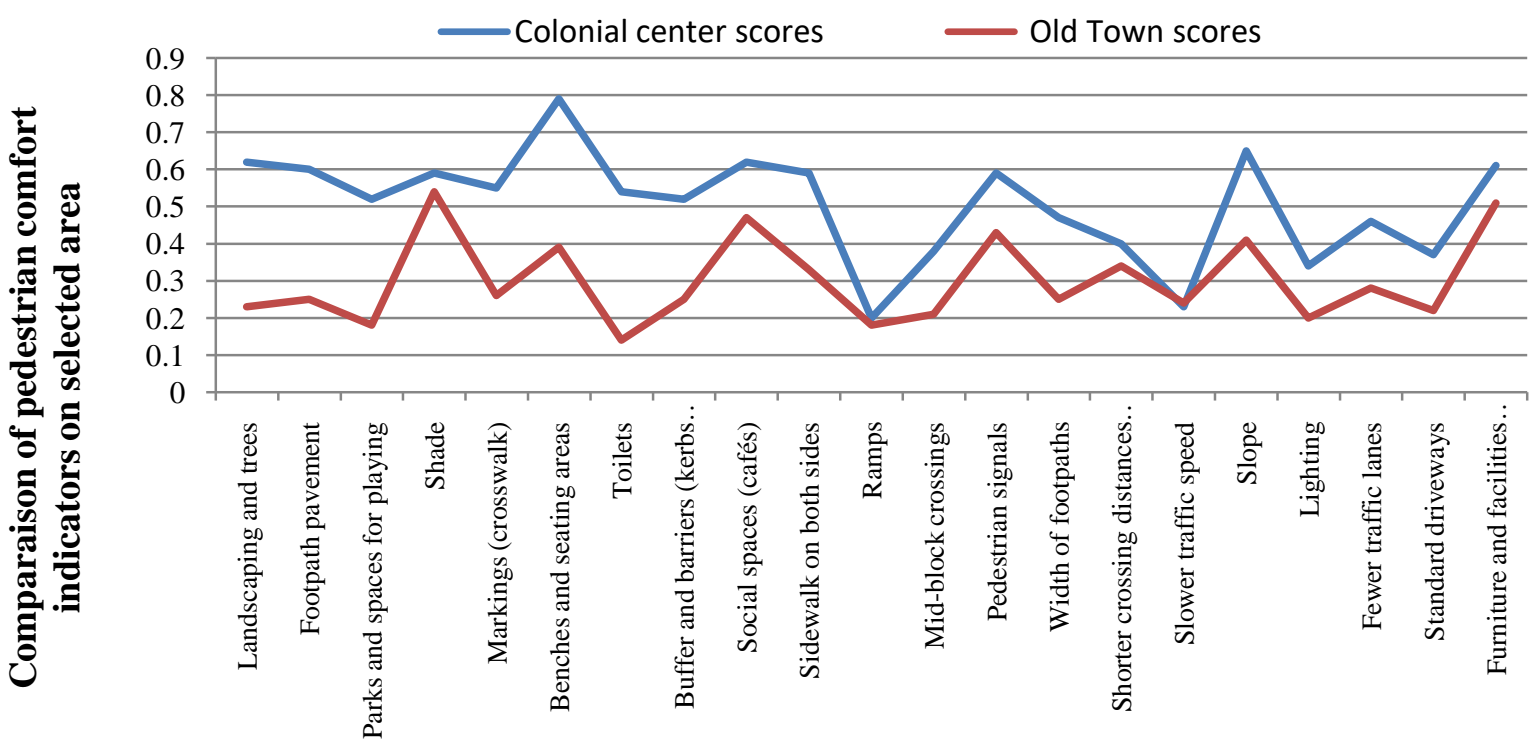

Pesdestrian comfort indicators

5

Fig. 3. Comparison of the pedestrian comfort indicators scores in the two selected neighbourhoods.

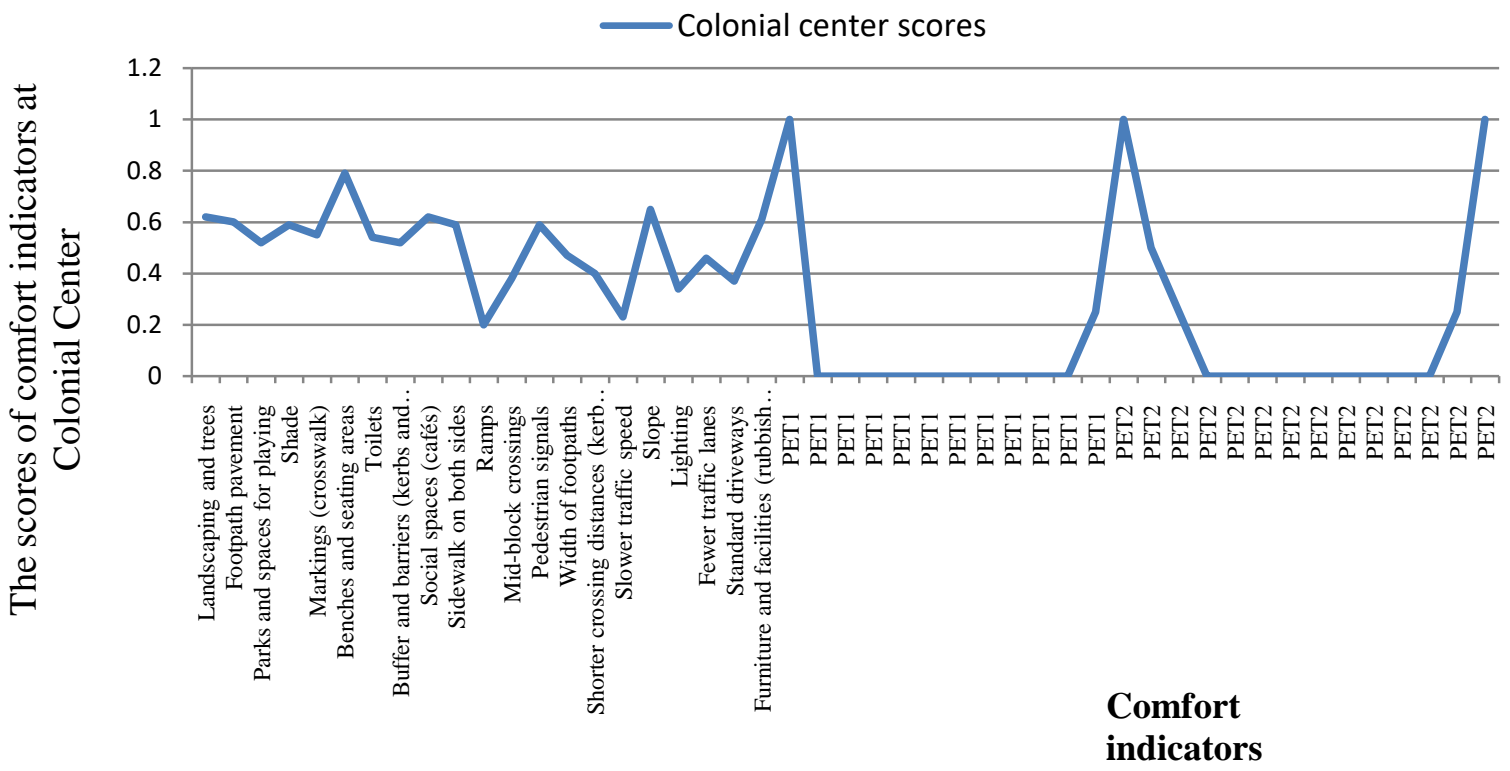

Fig. 4. Scores for pedestrian facilities and PET values in the Colonial Centre on two representative summer days 


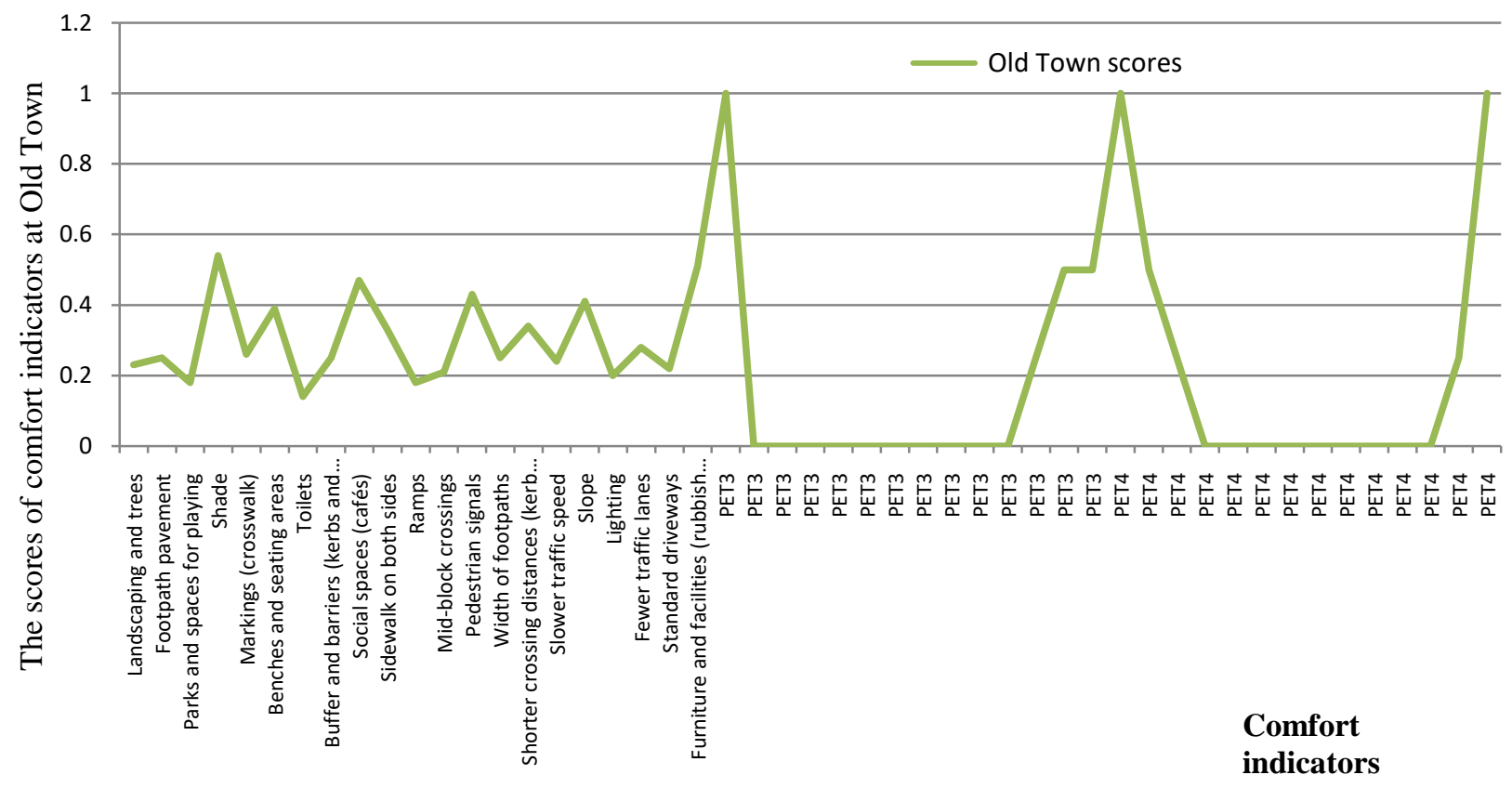

Fig. 5. Scores for pedestrian facilities and PET values in the Old Town on two representative summer days

\subsection{PET values and scores in the two neighbourhoods}

PET1 and PET2 are the PET values in the Colonial Centre on 18 July and 8 August 2017, respectively; PET3 and PET4 are those in the Old Town on the same dates, respectively.

PET1-PET4 values indicate hourly differences. Table 6 summarises the PET values for the representative summer days ( 7 a.m. -8 a.m.) according to the TSV in a Csa. Figure 6 shows that PET1 and PET3 values are similar at the same hours of the day. The highest score is 1 at 7 a.m., which means that the thermal sensation is neutral; from 8 a.m. to 5 p.m., the score is 0 , reflecting a thermal perception of hot or very hot; at 6 .p.m. the PET value is 0.25 , indicating a thermal perception of warm. Between 7 p.m. and 8 p.m., there is a slightly warm thermal sensation, with a score of 0.5 (Table 6).

Figure 6 also shows that PET 2 and PET 4 scores are similar at the same hours of the day. The highest score is 1 at 7 a.m., indicating a neutral thermal sensation. However, at 8 
a.m., there are two PET scores of 1 and 0.5, indicating differing thermal perceptions, one neutral and the other slightly warm, respectively. At 9 a.m. and 7 p.m., the value of 0.25 indicates a warm thermal sensation. Between 10 a.m. and 6 p.m., the PET score is 0, indicating a hot or very hot thermal perception (Table 6).

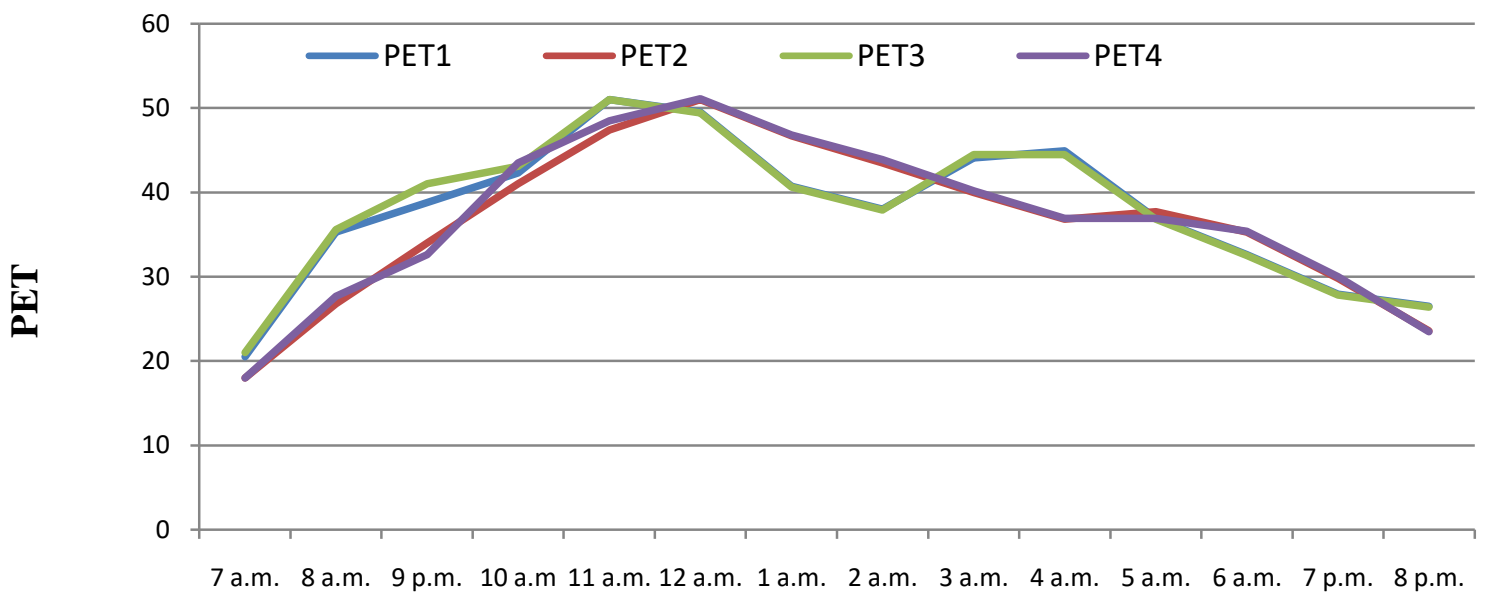

Time $(\mathrm{H})$

Fig. 6. Changes in PET values in the two selected areas on the two representative summer days.

Table 6.PET scores according to the TSV scale in a Csa.

\begin{tabular}{cccccccccc}
\hline Date/Time & \multicolumn{2}{c}{ Colonial Centre } & \multicolumn{2}{c}{ Old Town } & Date/Time & \multicolumn{2}{c}{$\begin{array}{c}\text { Colonial } \\
\text { Centre }\end{array}$} & \multicolumn{2}{c}{ Old Town } \\
18 July 17 & PET1 & Score & PET3 & Score & 08-08-17 & PET2 & Score & PET4 & Score \\
\hline 7 a.m. & 20.5 & 1 & 21 & 1 & 18 & 1 & 1 & 18 & 1 \\
8 a.m. & 35.3 & 0 & 35.6 & 0 & 26.8 & 0.5 & 0.5 & 27.7 & 0.5 \\
9 a.m. & 38.8 & 0 & 41 & 0 & 34 & 0.25 & 0.25 & 32.6 & 0.25 \\
10 a.m. & 42.3 & 0 & 43.1 & 0 & 41 & 0 & 0 & 43.5 & 0 \\
11 a.m. & 51 & 0 & 51 & 0 & 47.4 & 0 & 0 & 48.5 & 0 \\
12 p.m. & 49.5 & 0 & 49.4 & 0 & 51 & 0 & 0 & 51.1 & 0 \\
1 p.m. & 40.7 & 0 & 40.6 & 0 & 46.7 & 0 & 0 & 46.8 & 0 \\
2 p.m. & 38 & 0 & 37.9 & 0 & 43.5 & 0 & 0 & 43.9 & 0 \\
3 p.m. & 44.1 & 0 & 44.5 & 0 & 40 & 0 & 0 & 40.2 & 0 \\
4 p.m. & 44.9 & 0 & 44.5 & 0 & 36.8 & 0 & 0 & 36.9 & 0 \\
5 p.m. & 36.9 & 0 & 36.8 & 0 & 37.7 & 0 & 0 & 36.9 & 0 \\
6 p.m. & 32.6 & 0.25 & 32.5 & 0.25 & 35.3 & 0 & 0 & 35.4 & 0 \\
7 p.m. & 27.9 & 0.5 & 27.8 & 0.5 & 29.8 & 0.25 & 0.25 & 30 & 0.25 \\
8 p.m. & 26.5 & 0.5 & 26.4 & 0.5 & 23.6 & 1 & 1 & 23.5 & 1 \\
\hline
\end{tabular}




\subsection{The CWI}

We used Equation (1) to calculate the CWI in the two selected areas on the two representative summer days (18 July and 8 August 2017). Our estimated model explains the contributions of thermal comfort and pedestrian facilities to a pleasant walking experience.

The highest CWI value was $40.95 \%$ in the Colonial Centre on both representative days at 7 a.m. (Fig. 7), when the thermal sensation was neutral, defining a rarely acceptable average comfort quality that necessitates improvements (Table 1). The minimum CWI value was $37.09 \%$, that is, a hot thermal sensation, which indicated an uncomfortable walking experience. CWI reached new scores (38\% and 39\%) when the thermal perception was warm and slightly warm, respectively, with a lower classification which reflected uncomfortable conditions and low comfort quality (Fig. 7).

For the Old Town, the recorded scores were lower than for the Colonial Centre. The highest CWI value was $25.23 \%$ at 7 a.m. when the thermal sensation was neutral, illustrating uncomfortable comfort conditions and minimal pedestrian facilities. CWI reached its minimum value $(21.45 \%)$ when the thermal perception was hot, with increasing scores (22.32\% and $23.36 \%$ ) with a warm and slightly warm thermal sensation (Fig. 8). Despite these reported differences in thermal sensation, the CWI remained between $20 \%$ and $39 \%$, which indicates a low comfort quality level and needed improvements.

The results also showed that the CWI scores were almost identical over the two days, although thermal perception differed marginally depending on the time of day. For example, on 8 August, a neutral thermal sensation was recorded at 7 a.m. and 8 a.m., compared with only at 7 a.m. on 18 July, giving the highest CWI value in both neighbourhoods (40.95\% vs 25.23\%). The minimum CWI ratings (37.09\% and 21.36\%) occurred from 10 a.m. and remained constant until 6 p.m. on 8 August, compared with from 9 a.m. to 5 p.m. on 18 July, with a hot thermal sensation (Fig. 9). 


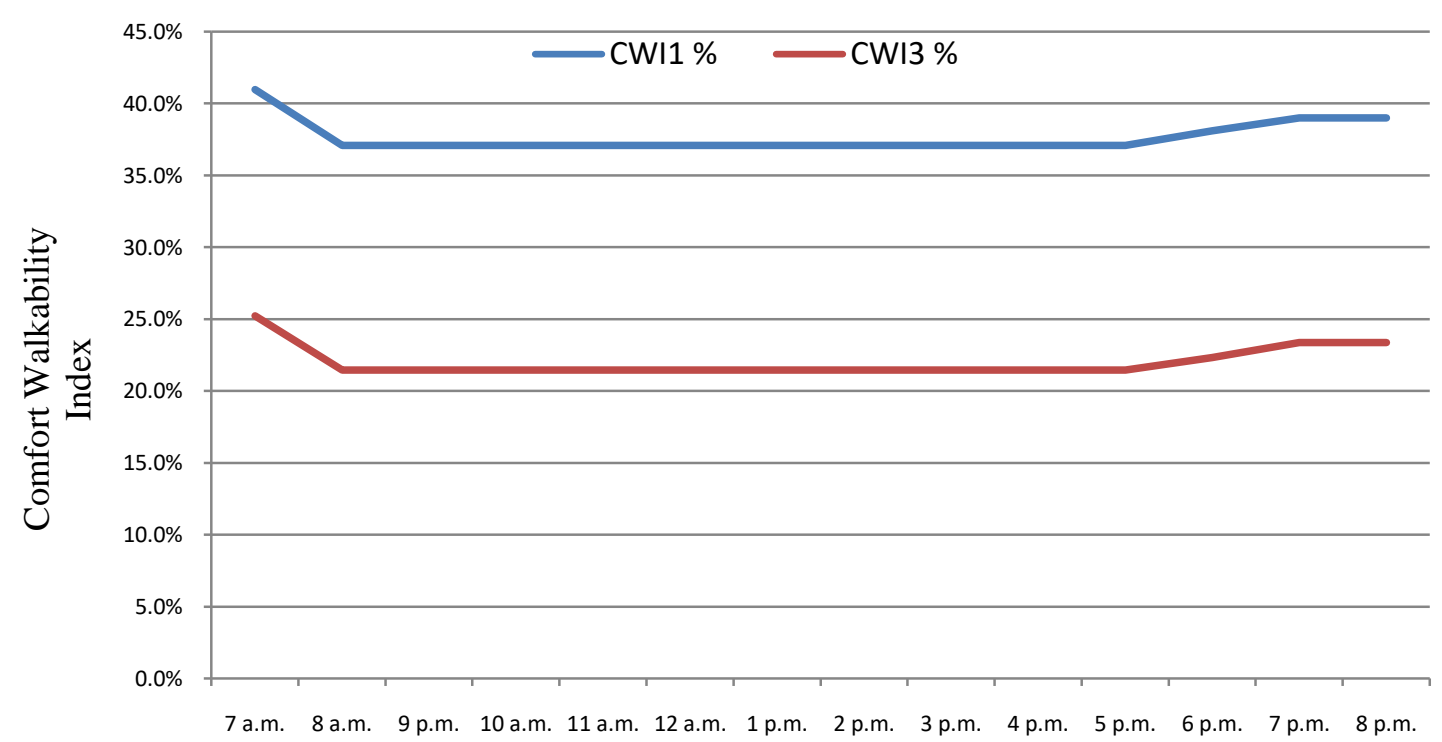

69 CWI 1: Comfort Walkability Index in Colonial centre, CWI3 Comfort WalkabikityIndex in Old Town.

70

71 Fig. 7. Changes in CWI in the two neighbourhoods on 18 July 2017.

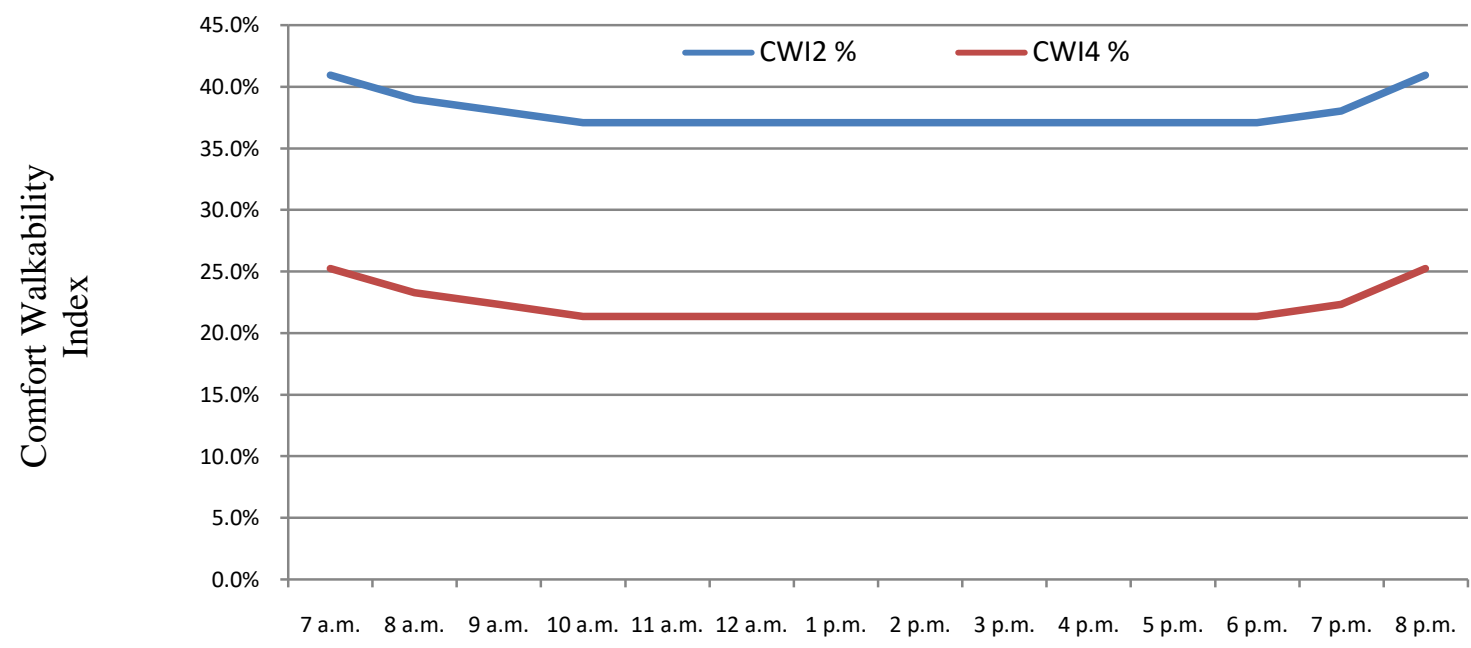

73 CWI2: Comfort Walkability Index in Colonial centre,CWI4 Comfort WalkabikityIndex in Old Town.

74 Fig. 8. Changes in CWI in the two neighbourhoods on 8 August 2017. 


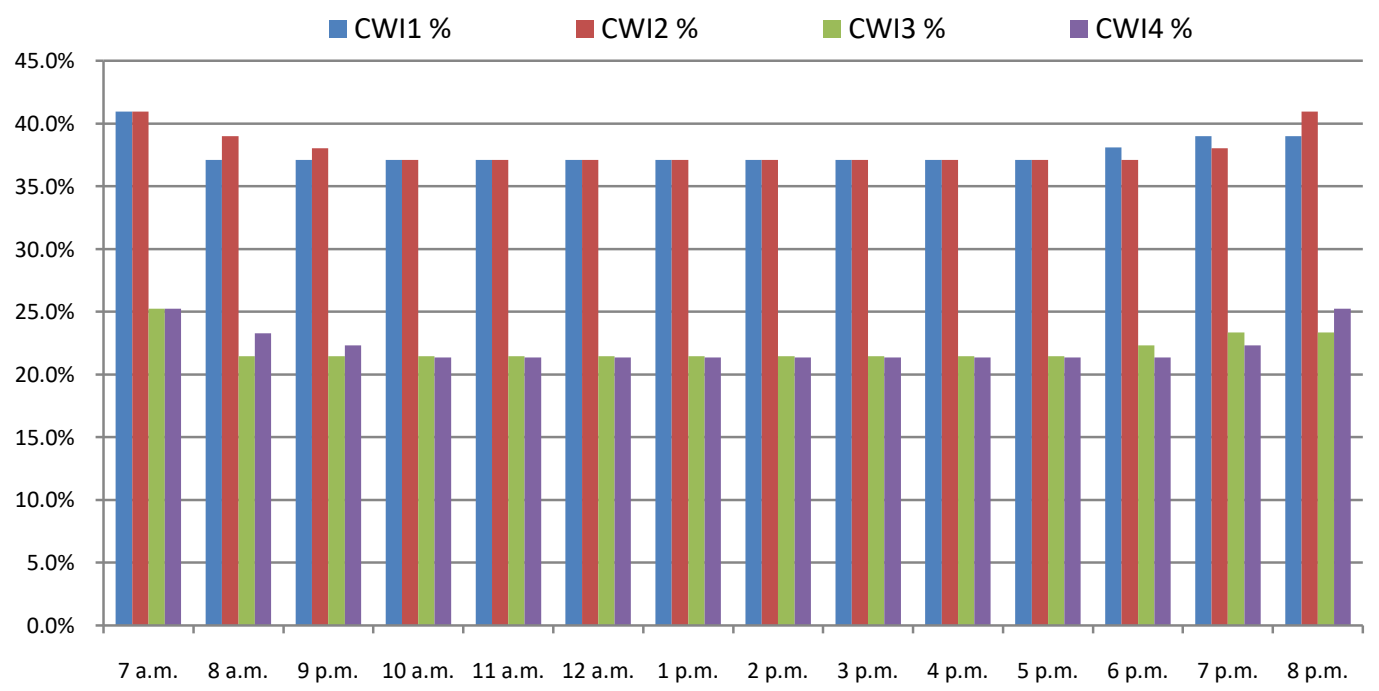

CWI 1: Comfort Walkability Index in Colonial centre, CWI3 Comfort Walkability Index in Old Town. (18/07/2017).

CWI2: Comfort Walkability Index in Colonial centre, CWI4 Comfort Walkability Index in Old Town. (08/08/2017).

Fig. 9. Changes in CWI in the two neighbourhoods on the two representative summer days.

\section{Discussion}

While most existing assessment tools evaluate sidewalks at the street level, few studies have examined sidewalks at the neighbourhood scale. The proposed model presents an easyto-follow method for the assessment of walkability comfort indicators on the neighbourhood micro scale.

\subsection{Coefficients and scores of pedestrian comfort facilities}

As revealed by the survey, landscaping and trees were estimated as the most significant indicator for respondents of the questionnaire (0.93), which highlighted their role in providing pleasant and attractive streets $[1,8]$, with a shady environment and landscaped views [12], thereby promoting rain infiltration and improving the local microclimate [44], as well as enhancing pedestrian safety $[8,14,22,93]$. Shade, parks and spaces for playing were also rated as very important in providing relaxation areas for inhabitants. 
Furthermore, these characteristics improve the attractiveness and security of walkways [44,94-96], enhancing well-being, comfort and health. Our results are also consistent with those of Aghaabbasi et al.[8], which emphasised the contribution of seating areas and benches to the attractiveness of sidewalks, and the convenience and comfort for pedestrians [97], especially for improved access for people with disabilities [48]. Moreover, these indicators can be considered as fundamental factors that affect pedestrian safety [35,98]. Mid-block crossings, slope and slower traffic speed are also considered important indicators because their absence generates an unpleasant effect on comfort and safety. Pedestrian signals had a weighting of 0.76 , which shows that they are a principal comfort indicator that ensures usability and safety [35].

Another important walkability indicator is path width, with a weighting of 0.75 ; clearly, path width can affect the comfort, attractiveness and safety of the walking experience [7,8]. However, some sidewalk features, such as lighting, fewer traffic lanes and standard driveways with a weighting of $0.67-0.71$ drew less attention than other comfort indicators. Rubbish bins had the lowest weighting of 0.32 .

The scores for each neighbourhood are related to people's perception of the area. Notably, the obtained scores corroborate that these perceptions are in line with actual conditions. For instance, in the Colonial Centre, furniture and facilities, rubbish bins, footpaths, sidewalks on both sides and pedestrian signals have high scores because this area is well maintained by the local authorities as a popular tourist location. The Colonial Centre also has a sufficient number of sitting areas and benches, social spaces (cafés), landscaping and trees, and shade (courts and squares), all of which are essential for the pedestrian comfort level. The Old Town scores are lower than the Colonial Centre for all comfort indicators except for slower traffic speed (Table 5). Owing to the layout of the medieval neighbourhood of the Old Town, with its twisting, irregular streets, vehicles in the area tend to respect speed 
limits. As presented in Table 3, the TSV considered in the summer period was varying between neutral, slightly warm, warm, hot and very hot.

Our analysis shows that PET values vary depending mainly on the time of day on the two representative days. The highest CWI values were neutral, for the lowest category of thermal sensation, followed by slightly warm and warm. The lowest CWI values were hot and very hot, for the highest category of thermal sensation.

The highest CWI values represent a neutral thermal sensation, which is considered an acceptable thermal comfort satisfaction level [60] during the summer period. Moreover, a neutral temperature is always related to a comfortable feeling [55]. The changes in the CWI during the two representative days in each neighbourhood reflect their dependence on the user's thermal sensation and comfortable weather conditions. Our findings are supported by those of Cohen et al. [89] and Givoni et al. [52], and confirm the importance of the climatic conditions in outdoor urban spaces and highlight their impact on quality of life and well-being in cities. Thus, a neutral thermal sensation characterises the recommended walking hours in the summer season $(18<$ PET<23.6), followed by a slightly warm $(26.8<$ PET $<27.9)$ and a warm $(29.8<$ PET<34) thermal sensation. In contrast, hot and very hot thermal sensations $(35.3<$ PET $<51)$ can be taken as uncomfortable walking conditions. It is of note that urban greening reduces daytime heat in the outdoor environment, and provides large areas of shade from tree canopies [85], thereby promoting walking even in the hot hours of the day.

To our knowledge, this study is the first to evaluate the walkability comfort level by including thermal comfort indices. The CWI tool has been developed to assess the standard pedestrian comfort features in neighbourhoods together with PET in a Csa. Comfort facilities and the thermal comfort of pedestrians encourage inhabitants to walk, thereby contributing to a healthy life. Moreover, the CWI indicated a good match with the real-life conditions in the two study areas. 
Application of these comfort indicators can lead to enhancing comfort quality and may

allow people to have a more pleasant walking experience in an urban environment. The CWI model would also help municipalities to improve the quality of life and contribute to increasing sustainable development strategies and health promotion. Our assessment tool indicated a strong correlation with the current real-life conditions of the two neighbourhoods studied, thereby confirming its reliability and reflecting the model-based performance. The model proposed in this study was applied to two different neighbourhoods in the city of Annaba, Algeria, by considering their distinct types of streets beside the suitability of considering PET as a thermal comfort indicator.PET was validated during different hours of the day considering air temperature, wind speed and relative humidity.CWI model is a relevant tool for the assessment of walkability including thermal comfort in different neighbourhood microscale level. In its initial design, this tool included a number of comfort indicators that were appropriate for all categories of users, such as slope, slower traffic speed, shorter crossing distances (kerb extensions) and ramps. However, there were some specific comfort indicators (e.g., drinking fountains, tactile pavements, skybridge lifts) that were not appropriate for the selected neighbourhoods due to their rare presence. Including potential thermal comfort indices such as the mean radiant temperature $\left(\mathrm{T}_{\mathrm{mrt}}\right)$ at the street scale allowed for enhanced precision with respect to PET values. Finally, using this model in other cities characterised by Csa or other climatic contexts represents a potential direction for future research. Exploring additional requirements on street level, such as microclimate measurement, shade or the UTCI index may provide an interesting alternative to evaluate thermal comfort effect on walkability as physical activity and provide additional comparative analysis for future research. 
during its completion. In particular, I would like to acknowledge the Local Environment

Management and Analysis (LEMA) group at the University of Liège. The funding for this

project was made possible through a research grant obtained from the Ministry of Higher

(PNE).

\section{References}

[1] Z. Asadi-Shekari, M. Moeinaddini, M. Aghaabbasi, M. Cools, and M. Zaly Shah, 'Exploring effective micro-level items for evaluating inclusive walking facilities on urban streets (applied in Johor Bahru, Malaysia)', Sustainable Cities and Society, vol. 49, p. 101563, Aug. 2019, doi: 10.1016/j.scs.2019.101563.

[2] D. Burden, 'Building Communities with Transportation', Transportation Research Record, vol. 1773, no. 1, pp. 5-20, Jan. 2001, doi: 10.3141/1773-02.

[3] M. Moeinaddini, Z. Asadi-Shekari, and M. Zaly Shah, 'An urban mobility index for evaluating and reducing private motorized trips', Measurement, vol. 63, pp. 30-40, Mar. 2015, doi: 10.1016/j.measurement.2014.11.026.

[4] A. Ruiz-Padillo, F. M. Pasqual, A. M. Larranaga Uriarte, and H. B. B. Cybis, 'Application of multicriteria decision analysis methods for assessing walkability: A case study in Porto Alegre, Brazil', Transportation Research Part D: Transport and Environment, vol. 63, pp. 855-871, Aug. 2018, doi: 10.1016/j.trd.2018.07.016.

[5] H. Badland et al., 'Using simple agent-based modeling to inform and enhance neighborhood walkability', Int J Health Geogr, vol. 12, no. 1, p. 58, 2013, doi: 10.1186/1476-072X-12-58.

[6] C. Boulange, C. Pettit, L. D. Gunn, B. Giles-Corti, and H. Badland, 'Improving planning analysis and decision making: The development and application of a Walkability Planning Support System', Journal of Transport Geography, vol. 69, pp. 129-137, May 2018, doi: 10.1016/j.jtrangeo.2018.04.017.

[7] M. Aghaabbasi, M. Moeinaddini, M. Zaly Shah, and Z. Asadi-Shekari, 'A new assessment model to evaluate the microscale sidewalk design factors at the neighbourhood level', Journal of Transport \& Health, vol. 5, pp. 97-112, Jun. 2017, doi: 10.1016/j.jth.2016.08.012.

[8] M. Aghaabbasi, M. Moeinaddini, M. Zaly Shah, Z. Asadi-Shekari, and M. Arjomand Kermani, 'Evaluating the capability of walkability audit tools for assessing sidewalks', Sustainable Cities and Society, vol. 37, pp. 475-484, Feb. 2018, doi: 10.1016/j.scs.2017.12.001.

[9] F. Moura, P. Cambra, and A. B. Gonçalves, 'Measuring walkability for distinct pedestrian groups with a participatory assessment method: A case study in Lisbon', Landscape and Urban Planning, vol. 157, pp. 282-296, Jan. 2017, doi: 10.1016/j.landurbplan.2016.07.002.

[10] M. Habibian and A. Hosseinzadeh, 'Walkability index across trip purposes', Sustainable Cities and Society, vol. 42, pp. 216-225, Oct. 2018, doi: 10.1016/j.scs.2018.07.005. 
[11] C. M. Hall and Y. Ram, 'Walk score ${ }^{\circledR}$ and its potential contribution to the study of active transport and walkability: A critical and systematic review', Transportation Research Part D: Transport and Environment, vol. 61, pp. 310-324, Jun. 2018, doi: 10.1016/j.trd.2017.12.018.

[12] M. Taleai and E. Taheri Amiri, 'Spatial multi-criteria and multi-scale evaluation of walkability potential at street segment level: A case study of tehran', Sustainable Cities and Society, vol. 31, pp. 37-50, May 2017, doi: 10.1016/j.scs.2017.02.011.

[13] H. Wang and Y. Yang, 'Neighbourhood walkability: A review and bibliometric analysis', Cities, vol. 93, pp. 43-61, Oct. 2019, doi: 10.1016/j.cities.2019.04.015.

[14] B. W. Landis, V. R. Vattikuti, R. M. Ottenberg, D. S. McLeod, and M. Guttenplan, 'Modeling the Roadside Walking Environment: Pedestrian Level of Service', Transportation Research Record, vol. 1773, no. 1, pp. 82-88, Jan. 2001, doi: 10.3141/1773-10.

[15] E. N. Ussery et al., 'Sampling methodology and reliability of a representative walkability audit', Journal of Transport \& Health, vol. 12, pp. 75-85, Mar. 2019, doi: 10.1016/j.jth.2018.11.007.

[16] P. Cambra, 'Pedestrian accessibility and attractiveness indicators for walkability assessment', Lisbon: Department of Civil Engineering and Architecture, Instituto Superior Técnico, Universidade Técnica de Lisboa, 2012.

[17] Sarkar S., 'Qualitative Evaluation of Comfort Needs in Urban Walkways in Major Activity Centers', Transportation Research Board, Washington, D.C, vol. 4, pp. 39-59, 2002.

[18] T. Akiyama and J. Kim, 'Transportation Policies for the Elderly and Disabled in Japan', International Journal of Urban Sciences, vol. 9, no. 2, pp. 87-98, Oct. 2005, doi: 10.1080/12265934.2005.9693575.

[19] U. Architectural and T. B. C. Board, 'Americans with Disabilities Act (ADA)', Accessibility Guidelines for Buildings and Facilities (ADAAG), 1992.

[20] K. J. Clifton, A. D. Livi Smith, and D. Rodriguez, 'The development and testing of an audit for the pedestrian environment', Landscape and Urban Planning, vol. 80, no. 1-2, pp. 95-110, Mar. 2007, doi: 10.1016/j.landurbplan.2006.06.008.

[21] A. B. Jacobs, 'Great streets', ACCESS Magazine, vol. 1, no. 3, pp. 23-27, 1993.

[22] Q. Lamour, A. M. Morelli, and K. R. de C. Marins, 'Improving walkability in a TOD context: Spatial strategies that enhance walking in the Belém neighbourhood, in São Paulo, Brazil', Case Studies on Transport Policy, vol. 7, no. 2, pp. 280-292, Jun. 2019, doi: 10.1016/j.cstp.2019.03.005.

[23] C. C. Marcus and C. Francis, People places: design guidlines for urban open space. John Wiley \& Sons, 1997.

[24] P. Cohen, O. Potchter, and A. Matzarakis, 'Human thermal perception of Coastal Mediterranean outdoor urban environments', Applied Geography, vol. 37, pp. 1-10, Feb. 2013, doi: 10.1016/j.apgeog.2012.11.001.

[25] M. Nikolopoulou and S. Lykoudis, 'Thermal comfort in outdoor urban spaces: Analysis across different European countries', Building and Environment, vol. 41, no. 11, pp. 1455-1470, Nov. 2006, doi: 10.1016/j.buildenv.2005.05.031.

[26] O. Potchter, P. Cohen, T.-P. Lin, and A. Matzarakis, 'Outdoor human thermal perception in various climates: A comprehensive review of approaches, methods and quantification', Science of The Total Environment, vol. 631-632, pp. 390-406, Aug. 2018, doi: 10.1016/j.scitotenv.2018.02.276.

[27] E. Johansson, S. Thorsson, R. Emmanuel, and E. Krüger, 'Instruments and methods in outdoor thermal comfort studies - The need for standardization', Urban Climate, vol. 10, pp. 346-366, Dec. 2014, doi: 10.1016/j.uclim.2013.12.002.

[28] Á. Gulyás, J. Unger, and A. Matzarakis, 'Assessment of the microclimatic and human comfort conditions in a complex urban environment: Modelling and measurements', Building and Environment, vol. 41, no. 12, pp. 1713-1722, Dec. 2006, doi: 10.1016/j.buildenv.2005.07.001.

[29] A. H. A. Mahmoud, 'Analysis of the microclimatic and human comfort conditions in an urban park in hot and arid regions', Building and Environment, vol. 46, no. 12, pp. 2641-2656, Dec. 2011, doi: 10.1016/j.buildenv.2011.06.025. 
[30] A. Matzarakis, F. Rutz, and H. Mayer, 'Modelling radiation fluxes in simple and complex environments-application of the RayMan model', Int J Biometeorol, vol. 51, no. 4, pp. 323334, Feb. 2007, doi: 10.1007/s00484-006-0061-8.

[31] S. Thorsson, T. Honjo, F. Lindberg, I. Eliasson, and E.-M. Lim, 'Thermal Comfort and Outdoor Activity in Japanese Urban Public Places', Environment and Behavior, vol. 39, no. 5, pp. 660684, Sep. 2007, doi: 10.1177/0013916506294937.

[32] M. Nikolopoulou and S. Lykoudis, 'Use of outdoor spaces and microclimate in a Mediterranean urban area', Building and Environment, vol. 42, no. 10, pp. 3691-3707, Oct. 2007, doi: 10.1016/j.buildenv.2006.09.008.

[33] M. Nikolopoulou, N. Baker, and K. Steemers, 'Thermal comfort in outdoor urban spaces: understanding the human parameter', Solar Energy, vol. 70, no. 3, pp. 227-235, 2001, doi: 10.1016/S0038-092X(00)00093-1.

[34] F. Costamagna, R. Lind, and O. Stjernström, 'Livability of Urban Public Spaces in Northern Swedish Cities: The Case of Umeå', Planning Practice \& Research, vol. 34, no. 2, pp. 131-148, Mar. 2019, doi: 10.1080/02697459.2018.1548215.

[35] M. Aghaabbasi, M. Moeinaddini, Z. Asadi-Shekari, and M. Z. Shah, 'The equitable use concept in sidewalk design', Cities, vol. 88, pp. 181-190, May 2019, doi: 10.1016/j.cities.2018.10.010.

[36] Z. Asadi-Shekari, M. Moeinaddini, and M. Zaly Shah, 'Pedestrian safety index for evaluating street facilities in urban areas', Safety Science, vol. 74, pp. 1-14, Apr. 2015, doi: 10.1016/j.ssci.2014.11.014.

[37] M. Kwon, C. Lee, and Y. Xiao, 'Exploring the role of neighborhood walkability on community currency activities: A case study of the crooked river alliance of TimeBanks', Landscape and Urban Planning, vol. 167, pp. 302-314, Nov. 2017, doi: 10.1016/j.landurbplan.2017.07.008.

[38] M. Nilles and I. Kaparias, 'Investigating the relation of highway design standards with networklevel walkability: The case study of Luxembourg', International Journal of Transportation Science and Technology, vol. 7, no. 4, pp. 254-263, Dec. 2018, doi: 10.1016/j.ijtst.2018.08.001.

[39] K. L. Cain et al., 'Developing and validating an abbreviated version of the Microscale Audit for Pedestrian Streetscapes (MAPS-Abbreviated)', Journal of Transport \& Health, vol. 5, pp. 84-96, Jun. 2017, doi: 10.1016/j.jth.2017.05.004.

[40] B. E. Saelens and S. L. Handy, 'Built Environment Correlates of Walking: A Review', Medicine \& Science in Sports \& Exercise, vol. 40, no. Supplement, pp. S550-S566, Jul. 2008, doi: 10.1249/MSS.0b013e31817c67a4.

[41] Z. Asadi-Shekari, M. Moeinaddini, and M. Zaly Shah, 'Disabled Pedestrian Level of Service Method for Evaluating and Promoting Inclusive Walking Facilities on Urban Streets', J. Transp. Eng., vol. 139, no. 2, pp. 181-192, Feb. 2013, doi: 10.1061/(ASCE)TE.1943-5436.0000492.

[42] K. R. Rahaman, J. M. Lourenço, and J. M. Viegas, 'Perceptions of Pedestrians and Shopkeepers in European Medium-Sized Cities: Study of Guimarães, Portugal', J. Urban Plann. Dev., vol. 138, no. 1, pp. 26-34, Mar. 2012, doi: 10.1061/(ASCE)UP.1943-5444.0000094.

[43] Z. Asadi-Shekari, M. Moeinaddini, and M. Zaly Shah, 'A pedestrian level of service method for evaluating and promoting walking facilities on campus streets', Land Use Policy, vol. 38, pp. 175-193, May 2014, doi: 10.1016/j.landusepol.2013.11.007.

[44] G. A. Battista and K. Manaugh, 'Stores and mores: Toward socializing walkability', Journal of Transport Geography, vol. 67, pp. 53-60, Feb. 2018, doi: 10.1016/j.jtrangeo.2018.01.004.

[45] L. B. Dixon, 'Bicycle and Pedestrian Level-of-Service Performance Measures and Standards for Congestion Management Systems', Transportation Research Record, vol. 1538, no. 1, pp. 1-9, Jan. 1996, doi: 10.1177/0361198196153800101.

[46] P. Grahn and U. A. Stigsdotter, 'Landscape planning and stress', Urban Forestry \& Urban Greening, vol. 2, no. 1, pp. 1-18, Jan. 2003, doi: 10.1078/1618-8667-00019.

[47] S. U. Jensen, 'Pedestrian and Bicyclist Level of Service on Roadway Segments', Transportation Research Record, vol. 2031, no. 1, pp. 43-51, Jan. 2007, doi: 10.3141/2031-06. 
[48] P. J. Troped et al., 'Development and Reliability and Validity Testing of an Audit Tool for Trail/Path Characteristics: The Path Environment Audit Tool (PEAT)', Journal of Physical Activity and Health, vol. 3, no. s1, pp. S158-S175, Feb. 2006, doi: 10.1123/jpah.3.s1.s158.

[49] J. Emery, C. Crump, and P. Bors, 'Reliability and Validity of Two Instruments Designed to Assess the Walking and Bicycling Suitability of Sidewalks and Roads', Am J Health Promot, vol. 18, no. 1, pp. 38-46, Sep. 2003, doi: 10.4278/0890-1171-18.1.38.

[50] K. R. Evenson, D. Sotres-Alvarez, A. H. Herring, L. Messer, B. A. Laraia, and D. A. Rodríguez, 'Assessing urban and rural neighborhood characteristics using audit and GIS data: derivation and reliability of constructs', Int J Behav Nutr Phys Act, vol. 6, no. 1, p. 44, 2009, doi: 10.1186/1479-5868-6-44.

[51] B. E. Saelens, J. F. Sallis, J. B. Black, and D. Chen, 'Neighborhood-Based Differences in Physical Activity: An Environment Scale Evaluation', Am J Public Health, vol. 93, no. 9, pp. 1552-1558, Sep. 2003, doi: 10.2105/AJPH.93.9.1552.

[52] Givoni, B, Noguchi, M., Saaroni, H., Pochter, O., Yaacov, Y, and Feller, N, 'Outdoor comfort research issues.', Energy and Buildings, vol. 1, pp. 77-86, 2003.

[53] I. Knez and S. Thorsson, 'Influences of culture and environmental attitude on thermal, emotional and perceptual evaluations of a public square', Int J Biometeorol, vol. 50, no. 5, pp. 258-268, May 2006, doi: 10.1007/s00484-006-0024-0.

[54] J. Spagnolo and R. de Dear, 'A field study of thermal comfort in outdoor and semi-outdoor environments in subtropical Sydney Australia', Building and Environment, vol. 38, no. 5, pp. 721-738, May 2003, doi: 10.1016/S0360-1323(02)00209-3.

[55] M. H. Elnabawi, N. Hamza, and S. Dudek, 'Thermal perception of outdoor urban spaces in the hot arid region of Cairo, Egypt', Sustainable Cities and Society, vol. 22, pp. 136-145, Apr. 2016, doi: 10.1016/j.scs.2016.02.005.

[56] R.-L. Hwang, T.-P. Lin, and A. Matzarakis, 'Seasonal effects of urban street shading on long-term outdoor thermal comfort', Building and Environment, vol. 46, no. 4, pp. 863-870, Apr. 2011, doi: 10.1016/j.buildenv.2010.10.017.

[57] N. Kántor, L. Égerházi, and J. Unger, 'Subjective estimation of thermal environment in recreational urban spaces-Part 1: investigations in Szeged, Hungary', Int J Biometeorol, vol. 56, no. 6, pp. 1075-1088, Nov. 2012, doi: 10.1007/s00484-012-0523-0.

[58] D. Lai, D. Guo, Y. Hou, C. Lin, and Q. Chen, 'Studies of outdoor thermal comfort in northern China', Building and Environment, vol. 77, pp. 110-118, Jul. 2014, doi: 10.1016/j.buildenv.2014.03.026.

[59] A. Tseliou, I. X. Tsiros, S. Lykoudis, and M. Nikolopoulou, 'An evaluation of three biometeorological indices for human thermal comfort in urban outdoor areas under real climatic conditions', Building and Environment, vol. 45, no. 5, pp. 1346-1352, May 2010, doi: 10.1016/j.buildenv.2009.11.009.

[60] ASHRAE Standard, 'American Society of Heating, Refrigerating and Air-Conditioning Engineers', vol. 55, no. 2004, 2004.

[61] H. Staiger, G. Laschewski, and A. Grätz, 'The perceived temperature - a versatile index for the assessment of the human thermal environment. Part A: scientific basics', Int J Biometeorol, vol. 56, no. 1, pp. 165-176, Jan. 2012, doi: 10.1007/s00484-011-0409-6.

[62] R. R. Gonzalez, Y. Nishi, and A. P. Gagge, 'Experimental evaluation of standard effective temperature a new biometeorological index of man's thermal discomfort', Int J Biometeorol, vol. 18, no. 1, pp. 1-15, Mar. 1974, doi: 10.1007/BF01450660.

[63] Pickup, J and de Dear, R, 'An outdoor thermal comfort index (OUT_SET*)-part I-the model and its assumptions. In Biometeorology and urban climatology at the turn of the millenium.', 2000, vol. 99, pp. 279-283.

[64] Jendritzky, G, de Dear, R, and Havenith, G, 'UTCI why another thermal index?', International Journal of Biometeorology, vol. 3, pp. 421-428, 2012. 
[65] A. Matzarakis, H. Mayer, and M. G. Iziomon, 'Applications of a universal thermal index: physiological equivalent temperature', International Journal of Biometeorology, vol. 43, no. 2, pp. 76-84, Oct. 1999, doi: 10.1007/s004840050119.

[66] H. Mayer and P. Höppe, 'Thermal comfort of man in different urban environments', Theor Appl Climatol, vol. 38, no. 1, pp. 43-49, 1987, doi: 10.1007/BF00866252.

[67] S. Berkovic, A. Yezioro, and A. Bitan, 'Study of thermal comfort in courtyards in a hot arid climate', Solar Energy, vol. 86, no. 5, pp. 1173-1186, May 2012, doi: 10.1016/j.solener.2012.01.010.

[68] C. R. de Freitas and E. A. Grigorieva, 'A comprehensive catalogue and classification of human thermal climate indices', Int J Biometeorol, vol. 59, no. 1, pp. 109-120, Jan. 2015, doi: 10.1007/s00484-014-0819-3.

[69] D. Lai, C. Zhou, J. Huang, Y. Jiang, Z. Long, and Q. Chen, 'Outdoor space quality: A field study in an urban residential community in central China', Energy and Buildings, vol. 68, pp. 713-720, Jan. 2014, doi: 10.1016/j.enbuild.2013.02.051.

[70] Y.-C. Chen and A. Matzarakis, 'Modified physiologically equivalent temperature-basics and applications for western European climate', Theor Appl Climatol, vol. 132, no. 3-4, pp. 12751289, May 2018, doi: 10.1007/s00704-017-2158-x.

[71] K. Błażejczyk et al., 'Principles of the New Universal Thermal Climate Index (UTCI) and its Application to Bioclimatic Research in European Scale', Miscellanea Geographica, vol. 14, no. 1, pp. 91-102, Dec. 2010, doi: 10.2478/mgrsd-2010-0009.

[72] A. Matzarakis, F. Rutz, and H. Mayer, 'Modelling radiation fluxes in simple and complex environments: basics of the RayMan model', Int J Biometeorol, vol. 54, no. 2, pp. 131-139, Mar. 2010, doi: 10.1007/s00484-009-0261-0.

[73] F. Ali-Toudert and H. Mayer, 'Thermal comfort in an east-west oriented street canyon in Freiburg (Germany) under hot summer conditions', Theor. Appl. Climatol., vol. 87, no. 1-4, pp. 223-237, Jan. 2007, doi: 10.1007/s00704-005-0194-4.

[74] H. Andrade, M.-J. Alcoforado, and S. Oliveira, 'Perception of temperature and wind by users of public outdoor spaces: relationships with weather parameters and personal characteristics', Int J Biometeorol, vol. 55, no. 5, pp. 665-680, Sep. 2011, doi: 10.1007/s00484-010-0379-0.

[75] I. Charalampopoulos, I. Tsiros, A. Chronopoulou-Sereli, and A. Matzarakis, 'Analysis of thermal bioclimate in various urban configurations in Athens, Greece', Urban Ecosyst, vol. 16, no. 2, pp. 217-233, Jun. 2013, doi: 10.1007/s11252-012-0252-5.

[76] T.-P. Lin, K.-T. Tsai, C.-C. Liao, and Y.-C. Huang, 'Effects of thermal comfort and adaptation on park attendance regarding different shading levels and activity types', Building and Environment, vol. 59, pp. 599-611, Jan. 2013, doi: 10.1016/j.buildenv.2012.10.005.

[77] T.-P. Lin and A. Matzarakis, 'Tourism climate and thermal comfort in Sun Moon Lake, Taiwan', Int J Biometeorol, vol. 52, no. 4, pp. 281-290, Mar. 2008, doi: 10.1007/s00484-007-0122-7.

[78] A. Matzarakis and H. Mayer, 'Another Kind of Environmental Stress: Thermal Stress. WHO Collaborating Centre for Air Quality Management and Air Pollution Control', NEWSLETTERS, vol. 18, pp. 7-10, 1996.

[79] T.-P. Lin, 'Thermal perception, adaptation and attendance in a public square in hot and humid regions', Building and Environment, vol. 44, no. 10, pp. 2017-2026, Oct. 2009, doi: 10.1016/j.buildenv.2009.02.004.

[80] H. Tsukaguchi, U. Vandebona, K.-Y. Yeh, H.-C. Hsia, and H.-Y. Jung, 'Comparative Study of Pedestrian Travel Culture in Different Cities in Japan', Journal of the Eastern Asia Society for Transportation Studies, vol. 8, pp. 1164-1178, 2010, doi: 10.11175/easts.8.1164.

[81] P. P. Koh and Y. D. Wong, 'Comparing pedestrians' needs and behaviours in different land use environments', Journal of Transport Geography, vol. 26, pp. 43-50, Jan. 2013, doi: 10.1016/j.jtrangeo.2012.08.012.

[82] L. D. Gunn, T. L. King, S. Mavoa, K. E. Lamb, B. Giles-Corti, and A. Kavanagh, 'Identifying destination distances that support walking trips in local neighborhoods', Journal of Transport \& Health, vol. 5, pp. 133-141, Jun. 2017, doi: 10.1016/j.jth.2016.08.009. 
[83] W. Klemm, B. G. Heusinkveld, S. Lenzholzer, M. H. Jacobs, and B. Van Hove, 'Psychological and physical impact of urban green spaces on outdoor thermal comfort during summertime in The Netherlands', Building and Environment, vol. 83, pp. 120-128, Jan. 2015, doi: 10.1016/j.buildenv.2014.05.013.

[84] H. Lee, J. Holst, and H. Mayer, 'Modification of Human-Biometeorologically Significant Radiant Flux Densities by Shading as Local Method to Mitigate Heat Stress in Summer within Urban Street Canyons', Advances in Meteorology, vol. 2013, pp. 1-13, 2013, doi: $10.1155 / 2013 / 312572$.

[85] H. Lee, H. Mayer, and L. Chen, 'Contribution of trees and grasslands to the mitigation of human heat stress in a residential district of Freiburg, Southwest Germany', Landscape and Urban Planning, vol. 148, pp. 37-50, Apr. 2016, doi: 10.1016/j.landurbplan.2015.12.004.

[86] E. Andreou, 'Thermal comfort in outdoor spaces and urban canyon microclimate', Renewable Energy, vol. 55, pp. 182-188, Jul. 2013, doi: 10.1016/j.renene.2012.12.040.

[87] VDI, 'Methods for the human-biometeorological evaluation of climate and air quality for urban and regional planning.' 1998.

[88] T.-P. Lin, K.-T. Tsai, C.-C. Liao, and Y.-C. Huang, 'Effects of thermal comfort and adaptation on park attendance regarding different shading levels and activity types', Building and Environment, vol. 59, pp. 599-611, Jan. 2013, doi: 10.1016/j.buildenv.2012.10.005.

[89] P. Cohen, O. Potchter, and A. Matzarakis, 'Human thermal perception of Coastal Mediterranean outdoor urban environments', Applied Geography, vol. 37, pp. 1-10, Feb. 2013, doi: 10.1016/j.apgeog.2012.11.001.

[90] A. Matzarakis, H. Mayer, and M. G. Iziomon, 'Applications of a universal thermal index: physiological equivalent temperature', International Journal of Biometeorology, vol. 43, no. 2, pp. 76-84, Oct. 1999, doi: 10.1007/s004840050119.

[91] Köppen, 'Grundriss der klimakunde', 1931.

[92] Walkscore.com, 'Walkscore.com'. 2010, Accessed: Jul. 15, 2016. [Online]. Available: http://www.walkscore.com.

[93] A. Todorova, S. Asakawa, and T. Aikoh, 'Preferences for and attitudes towards street flowers and trees in Sapporo, Japan', Landscape and Urban Planning, vol. 69, no. 4, pp. 403-416, Oct. 2004, doi: 10.1016/j.landurbplan.2003.11.001.

[94] A. Adkins, J. Dill, G. Luhr, and M. Neal, 'Unpacking Walkability: Testing the Influence of Urban Design Features on Perceptions of Walking Environment Attractiveness', Journal of Urban Design, vol. 17, no. 4, pp. 499-510, Nov. 2012, doi: 10.1080/13574809.2012.706365.

[95] B. Giles-Corti et al., 'Increasing walking', American Journal of Preventive Medicine, vol. 28, no. 2, pp. 169-176, Feb. 2005, doi: 10.1016/j.amepre.2004.10.018.

[96] N. Owen, N. Humpel, E. Leslie, A. Bauman, and J. F. Sallis, 'Understanding environmental influences on walking', American Journal of Preventive Medicine, vol. 27, no. 1, pp. 67-76, Jul. 2004, doi: 10.1016/j.amepre.2004.03.006.

[97] M. Kihl, D. Brennan, N. Gabhawala, J. List, and P. Mittal, 'Livable communities: An evaluation guide', Washington, DC: AARP Public Policy Institute, 2005.

[98] M. J. Boisseau, 'Sidewalk accessibility: A study of the continuing needs of pedestrians applied to the sidewalk planning and design process', 1999. 